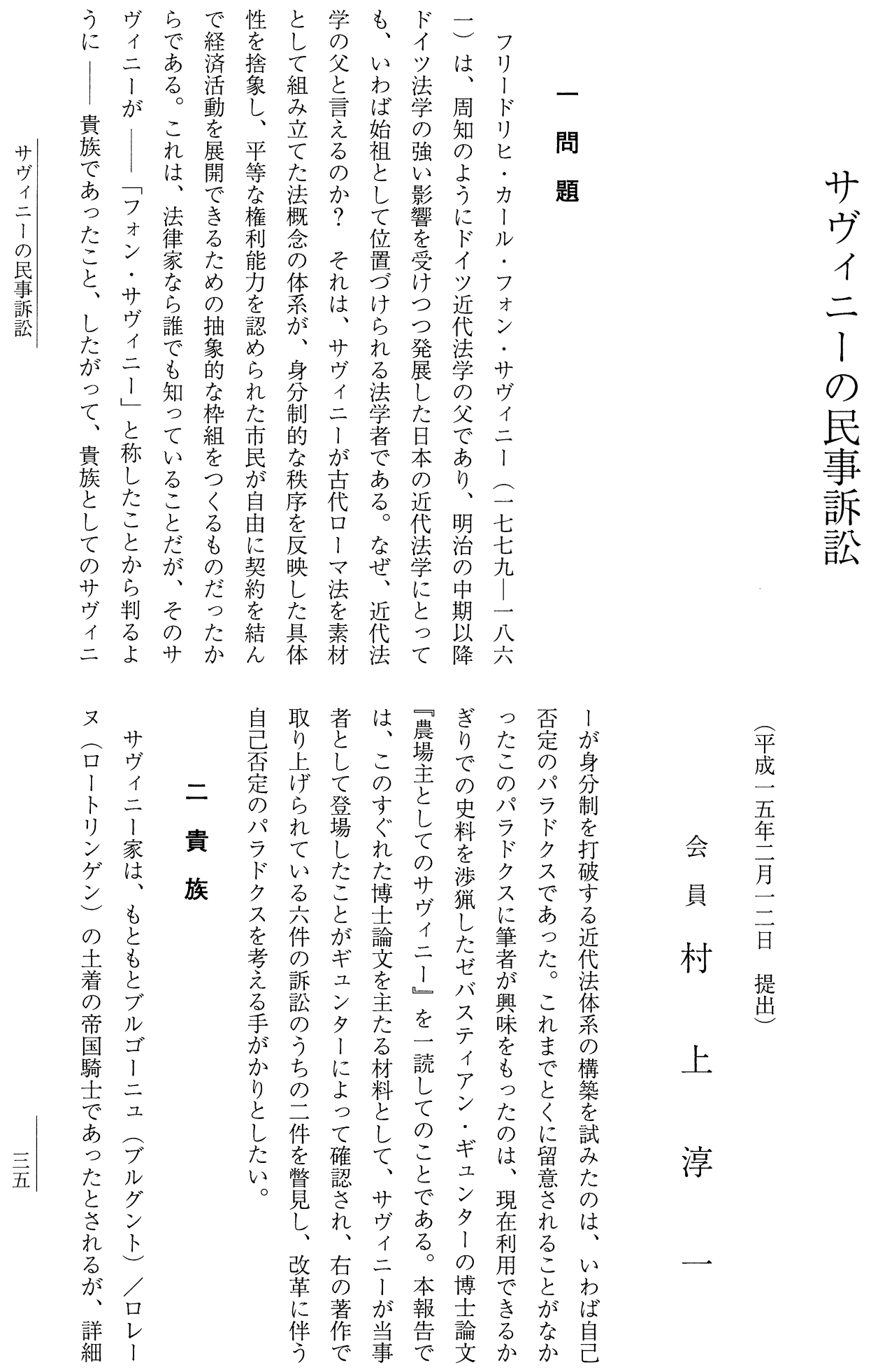



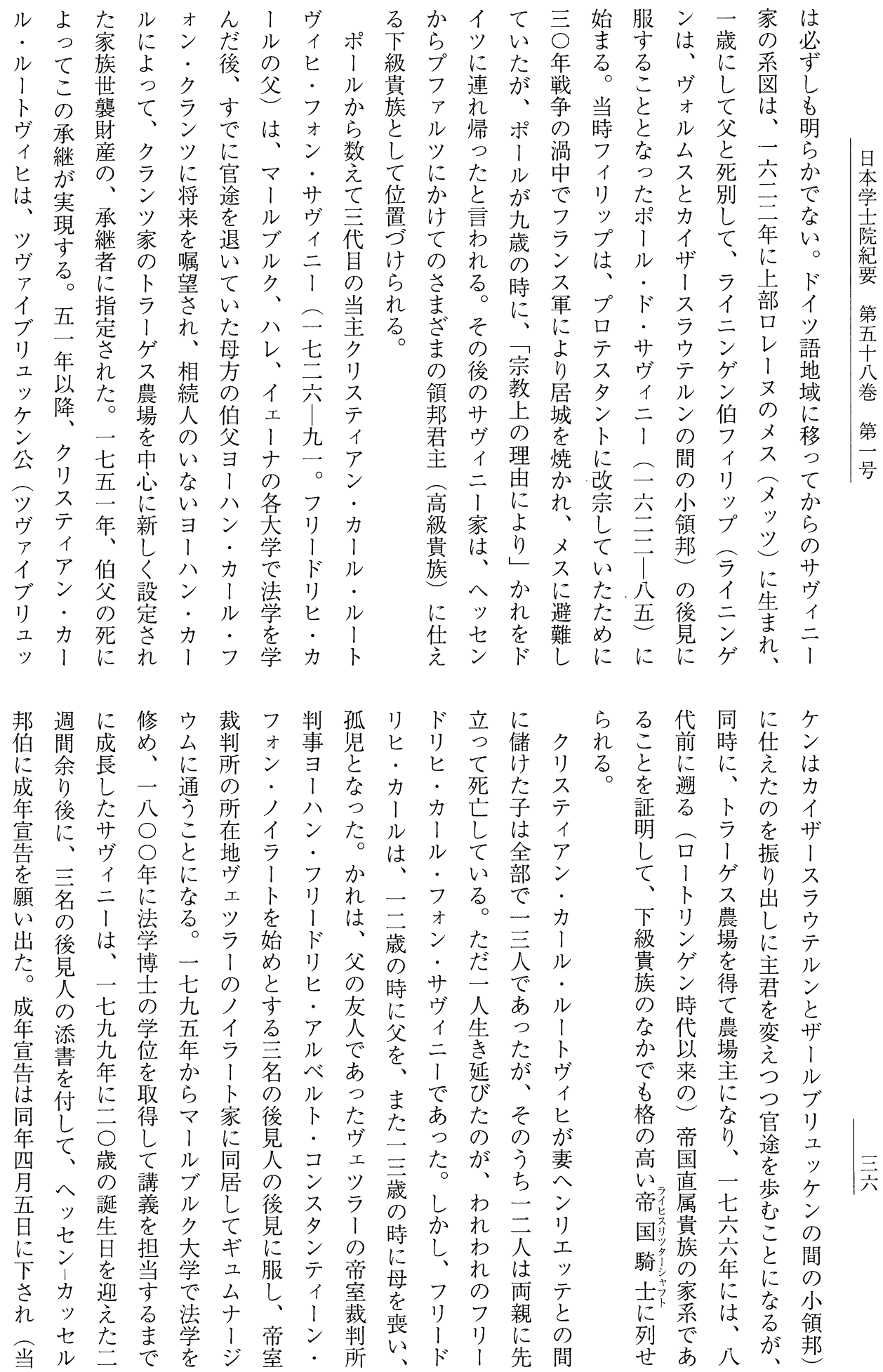

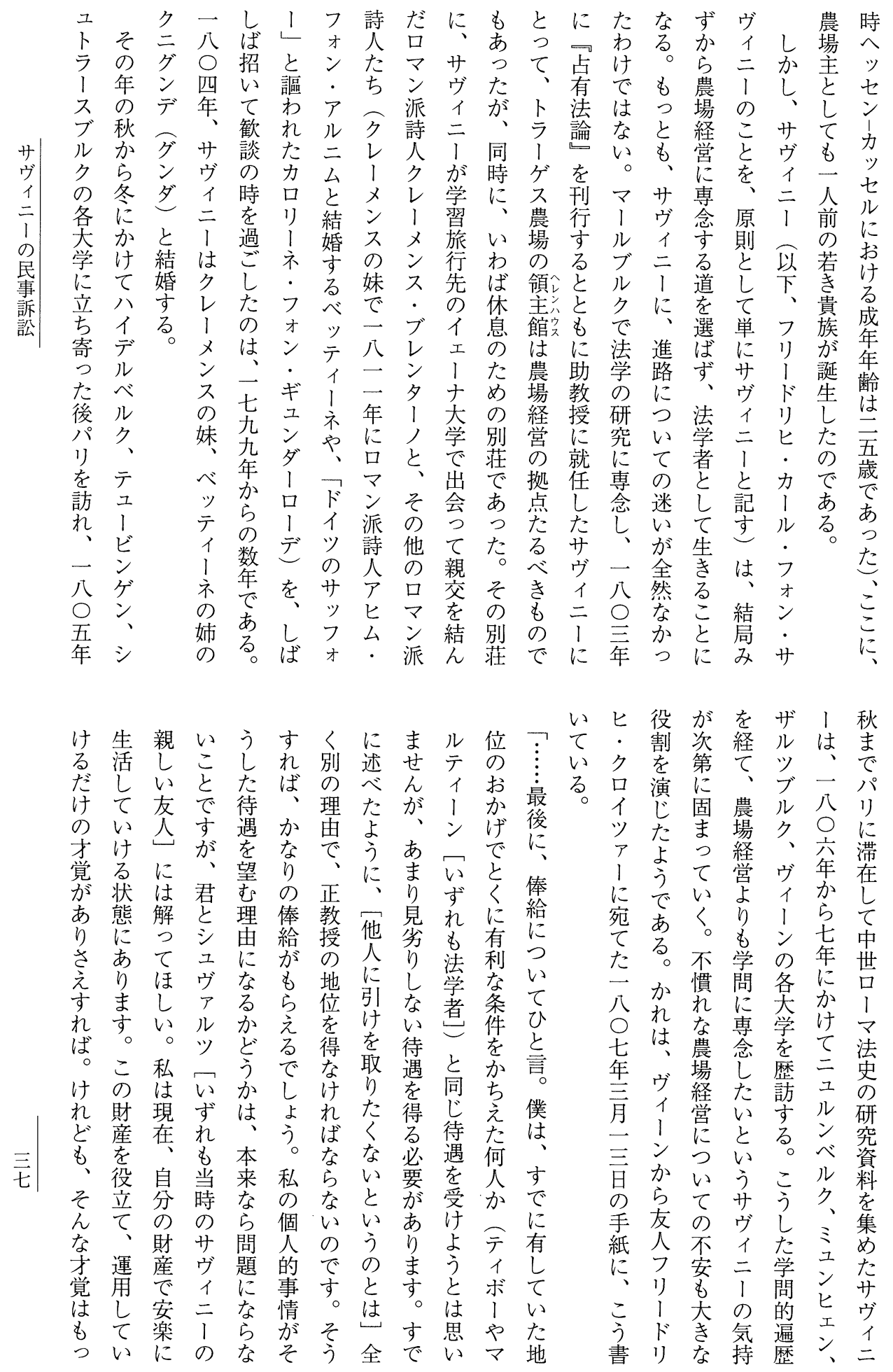


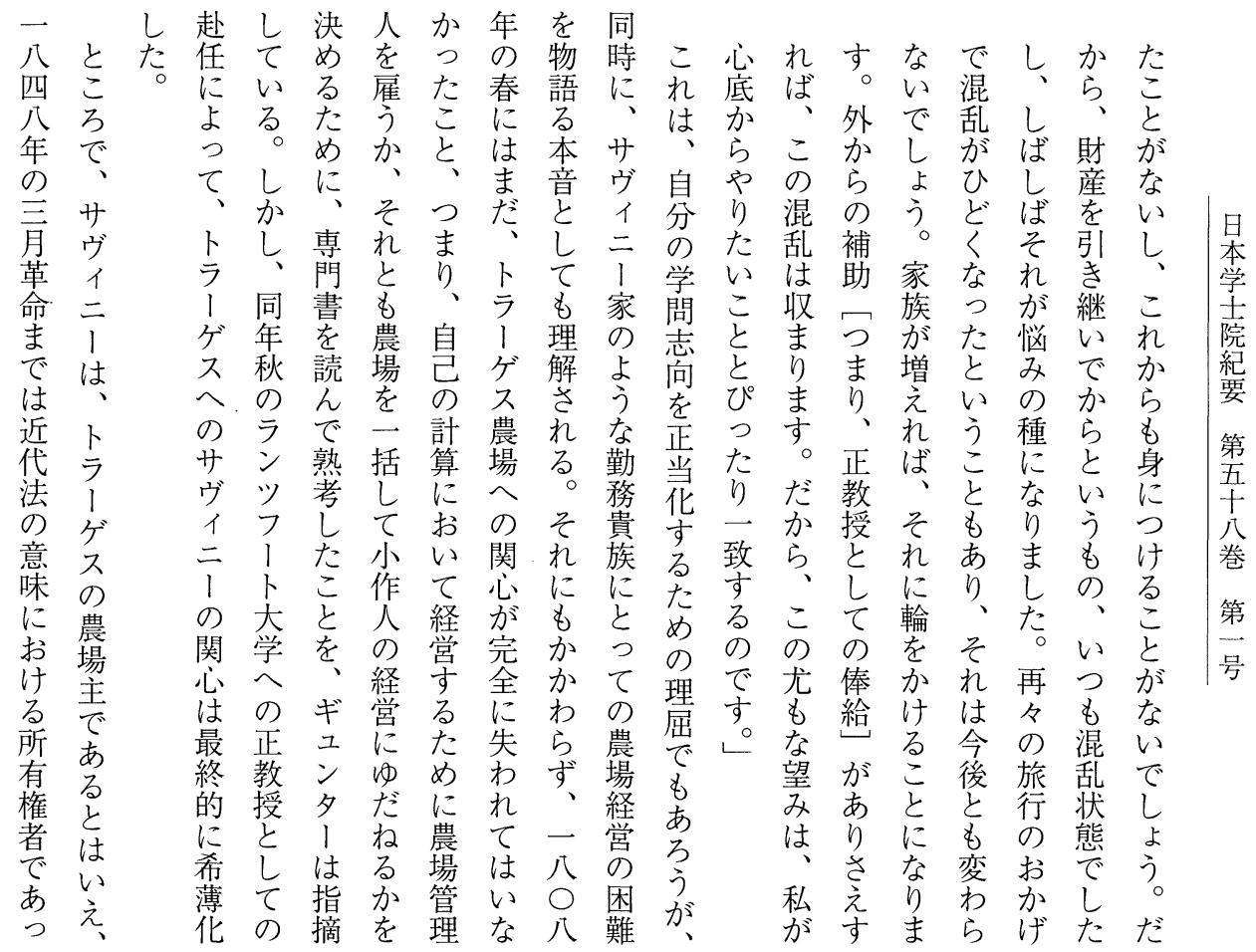

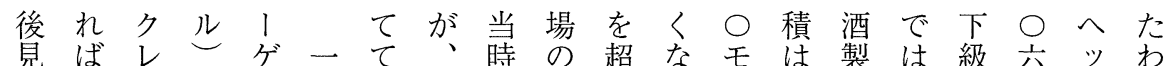
人扰、公向中以中充いル造牧所年七け のそバ経か○き庭来央るこゲ六架畜有がで

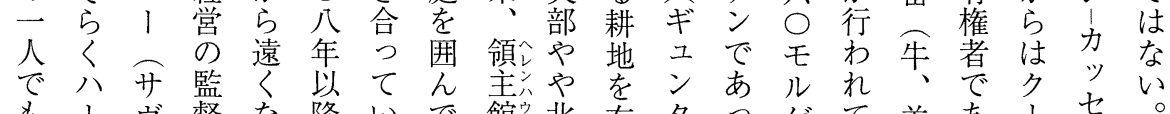

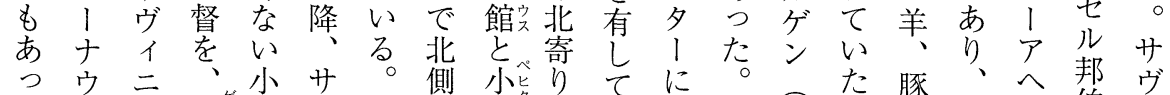

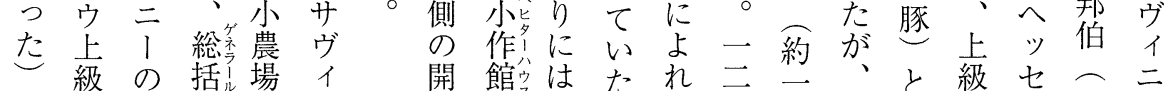

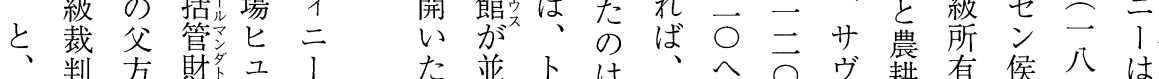

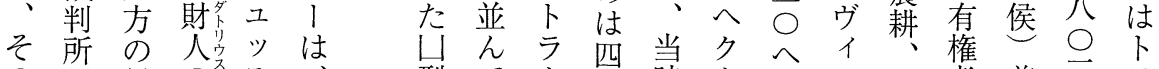

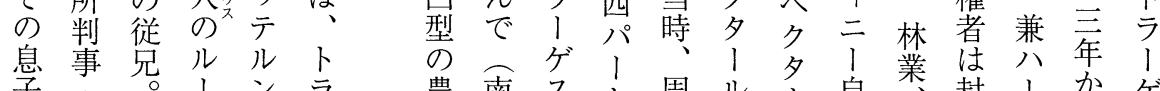
䀡事兄ル ル

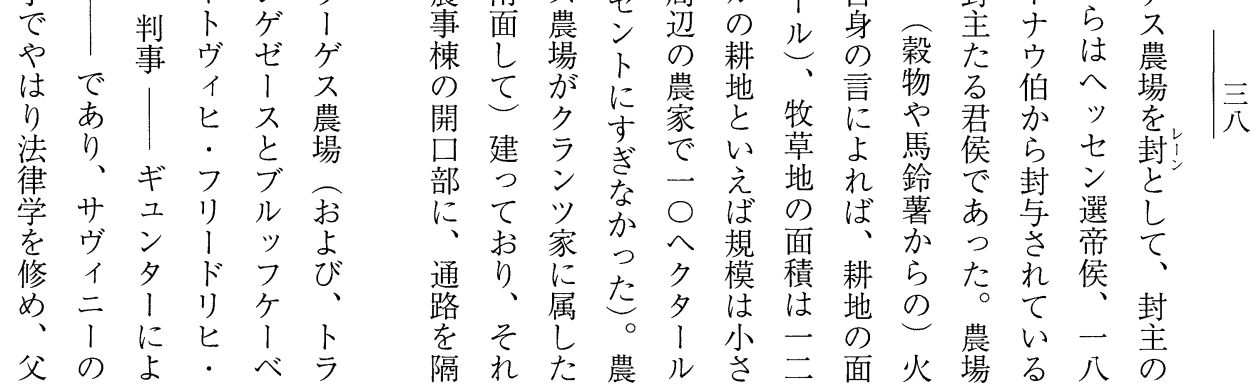



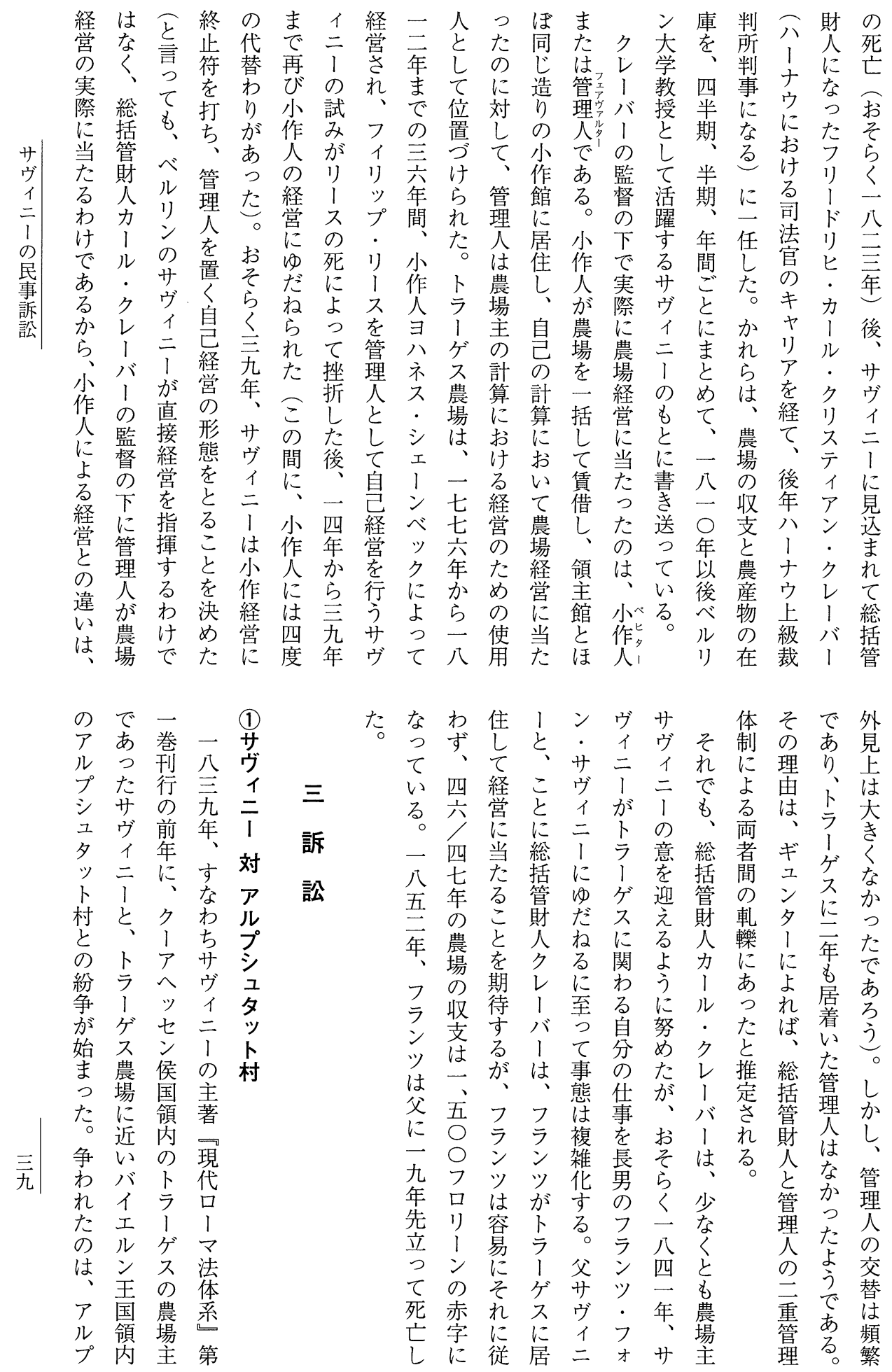


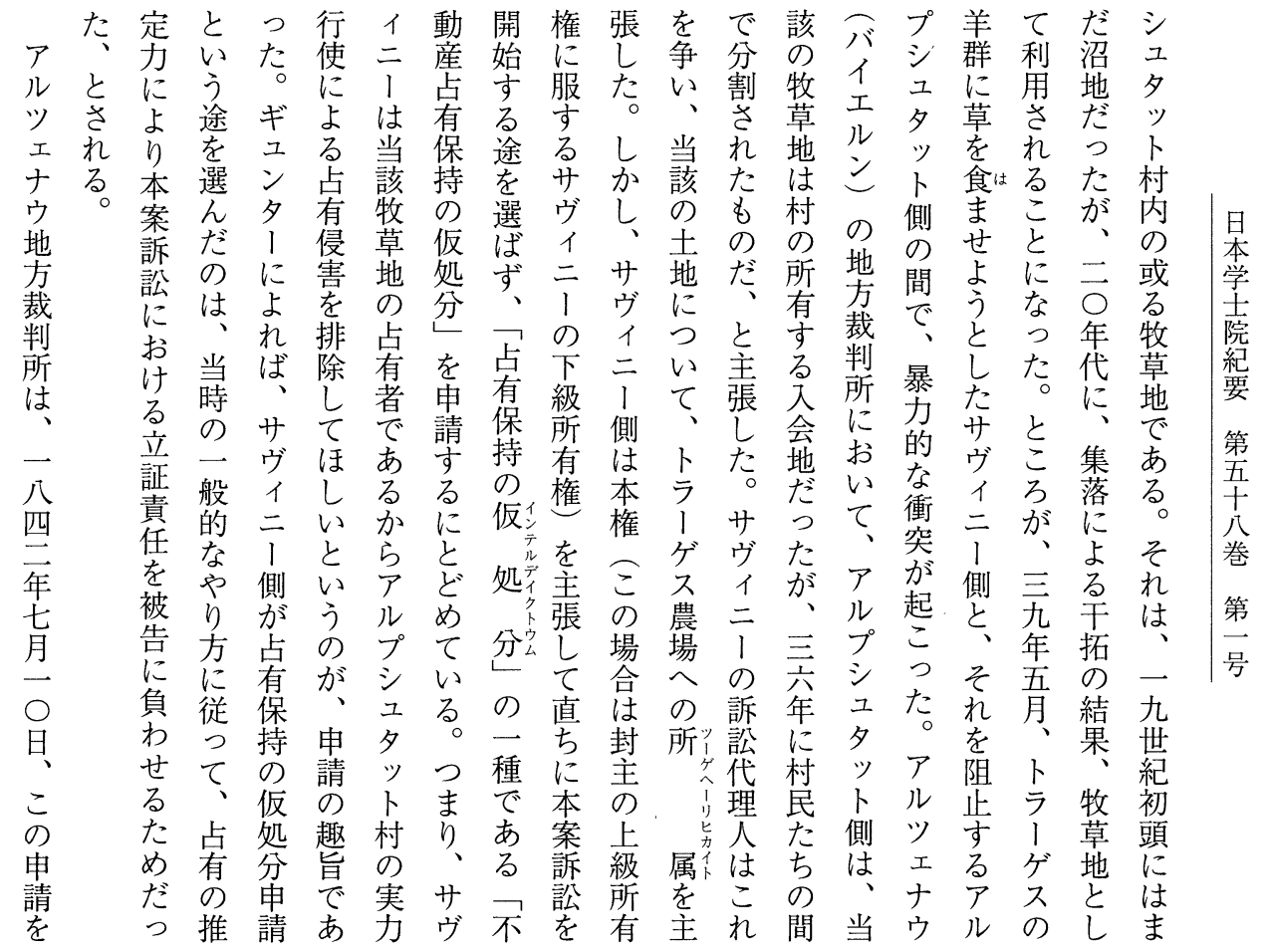

1すな見占授つの素素決いもをそ池は管イ認 は史いる有にた占のと定う加占れと轄工的

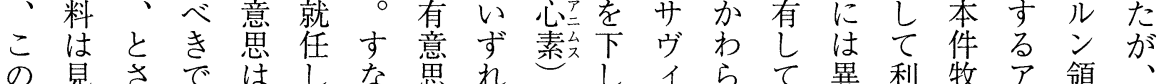

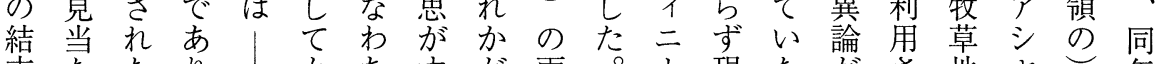
末たたり かちすが両。現たがさ地ヤ年

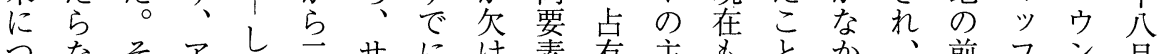

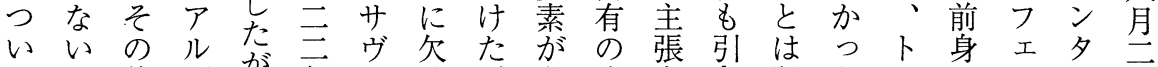
て、す後プ゙

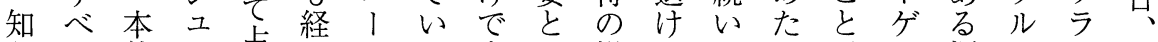
らて件夕号つがる、生さ場て て が、尔沼クンア れを裁ツ有てト、息で合抗自、つ農地控ケル る訴判卜息いラとるるに告分アま場が訴ン プ

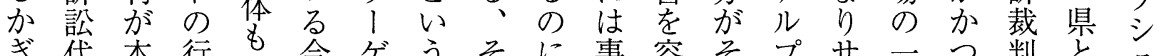

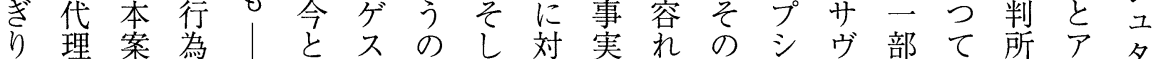
何人訴は 語任に訟占す 有でて 去 控 本での 仮 草 夕 二 み

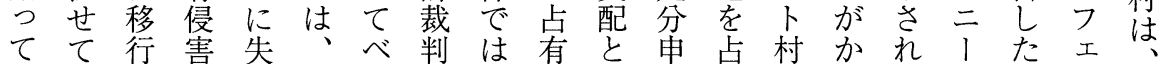
いいしとわサル所、の占請有につてに゚ン

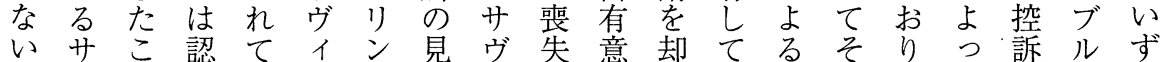

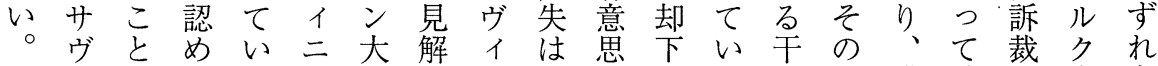

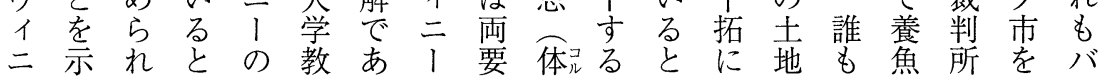




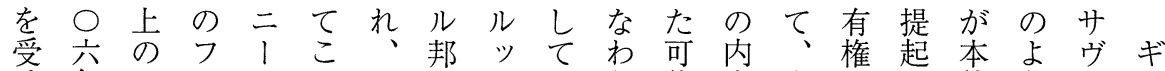

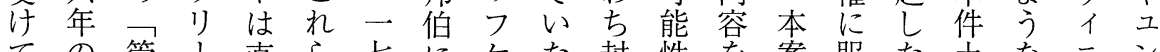
ての管は直ら七にケた封性を案服た高なニン い帝理ドちの七よ施地含訴子と地事 1 夕

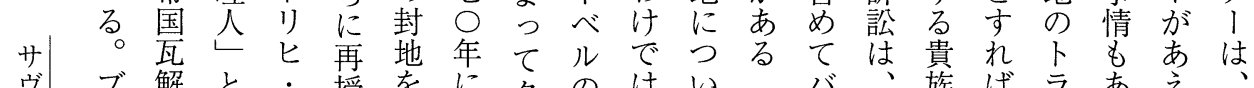

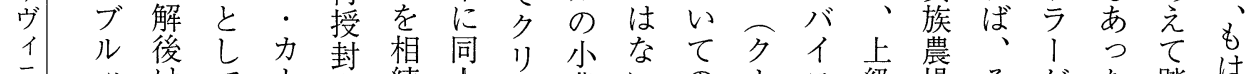
二

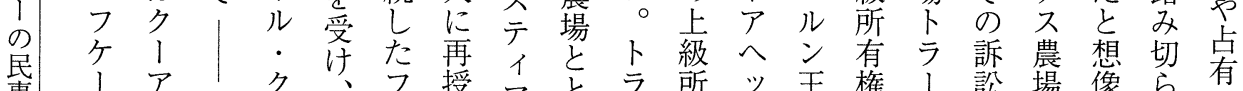

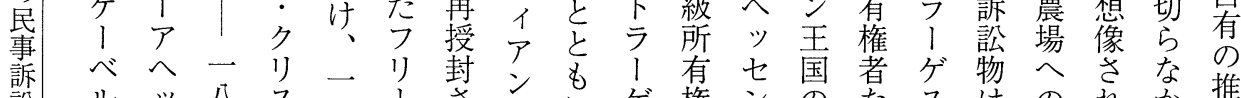

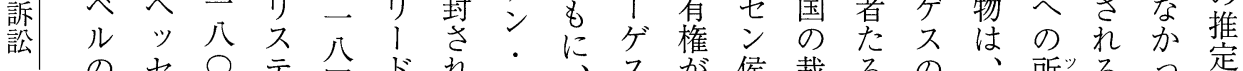

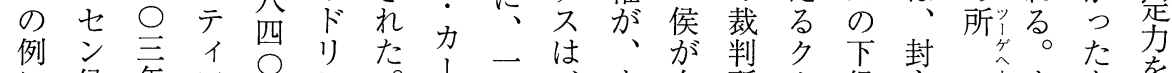

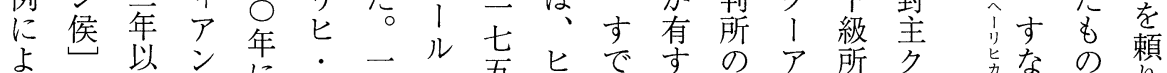

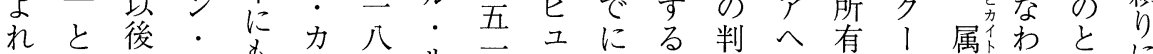

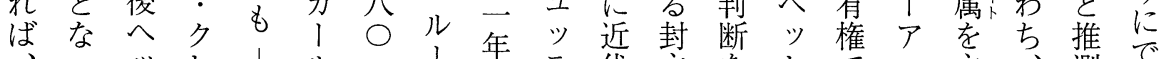
農だセ

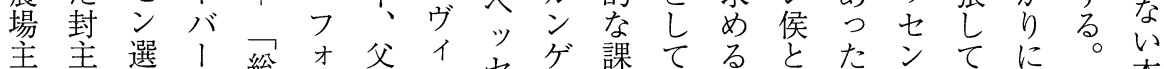

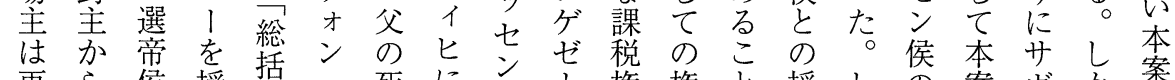

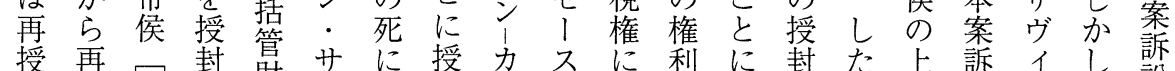

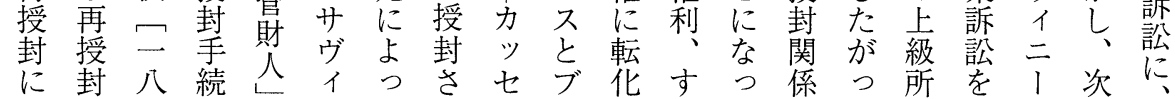

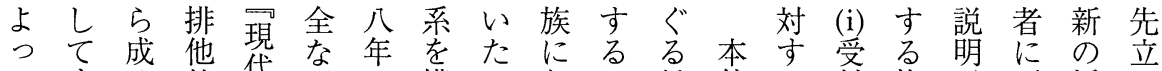
てまる的垈所の構のとに紛件る封権至授つ

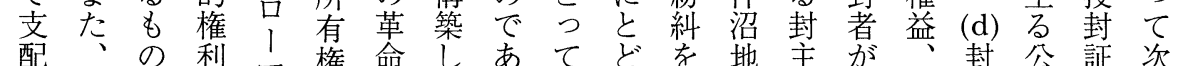
さもと利マ権に命し あててどを地主孞 封公証次 れはしと法二ょこて、るけい同に封のさ踣よ

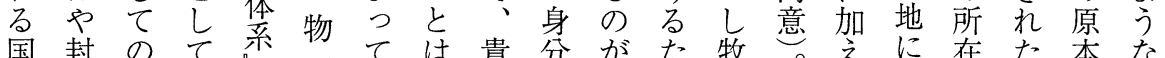
国封のて系—ては貴分がた牧。物在た本な 家主物所第権封、族制賢め草対系と調

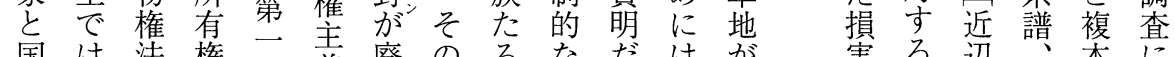

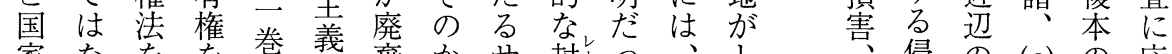

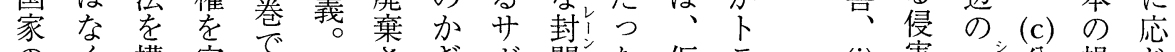

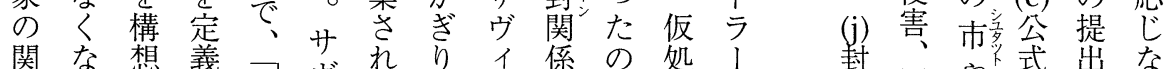

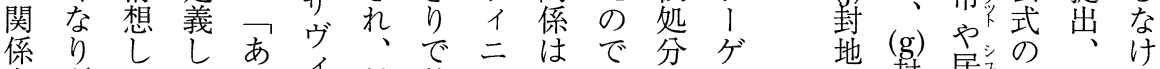

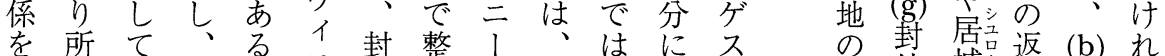
前有いそ人主合が扔なよ可地城、還初ば

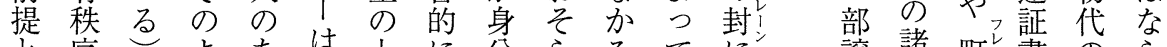

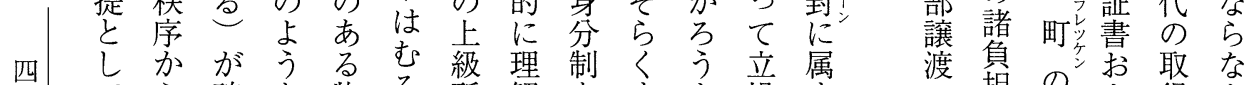

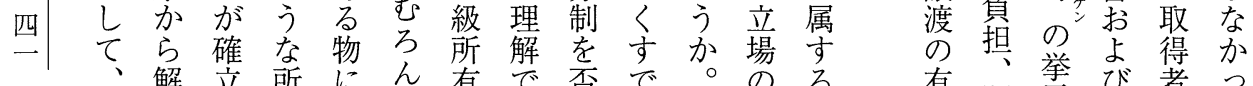

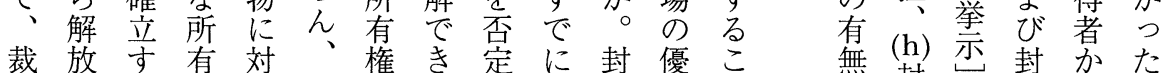

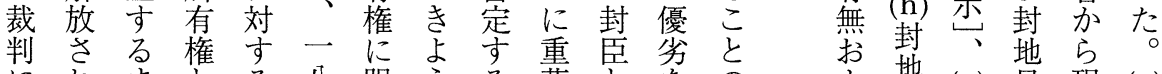

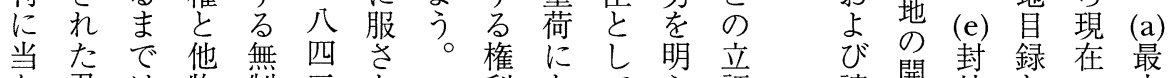

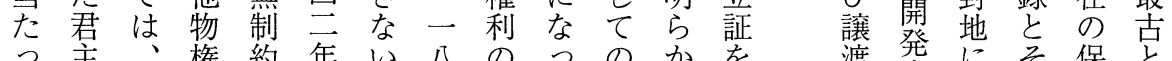

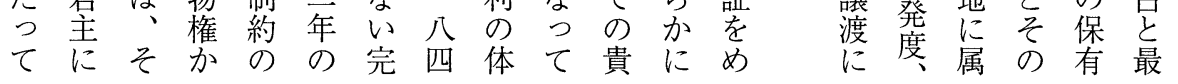




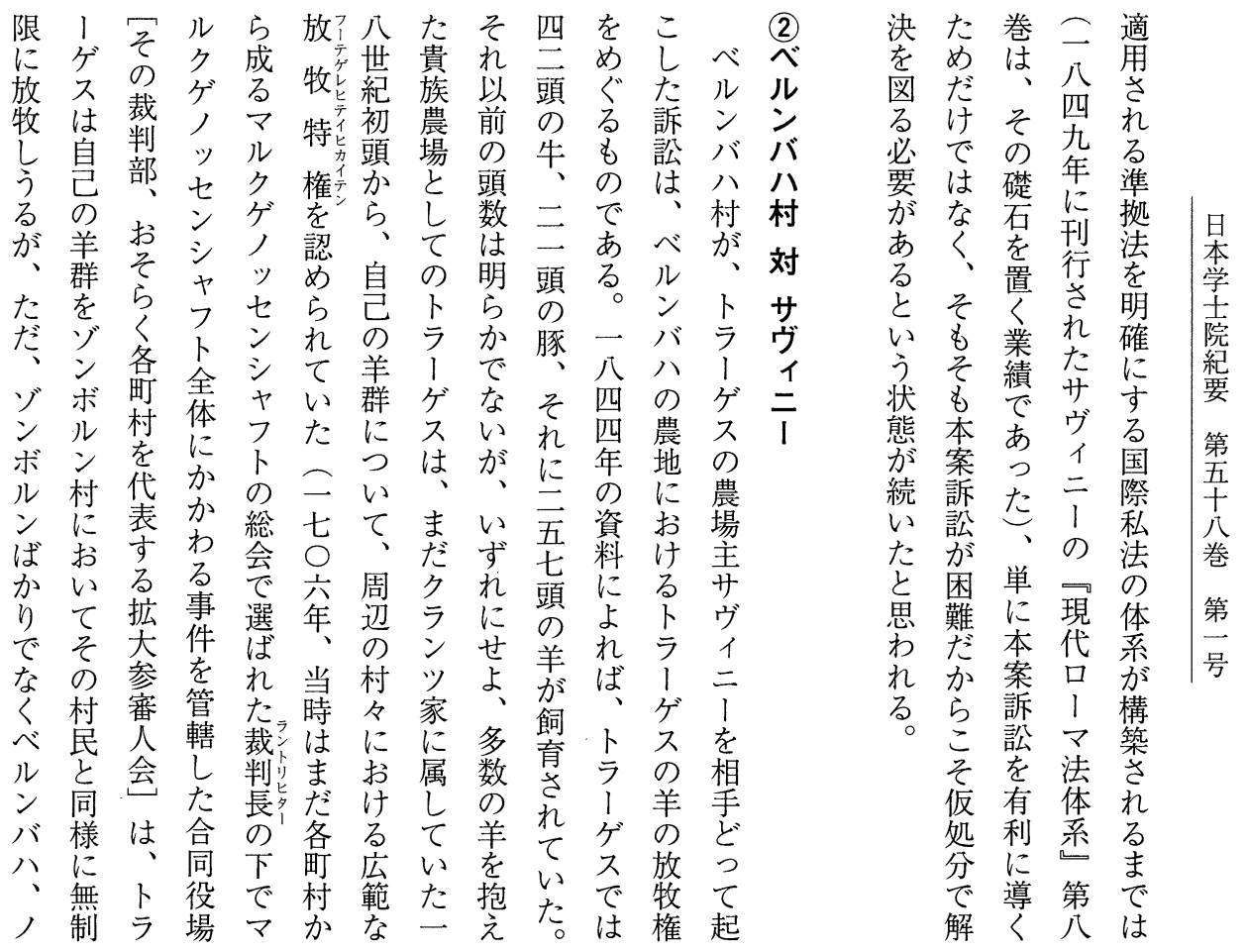

邦羊一し播用ク己るがいそシ問て羊ルは定イ

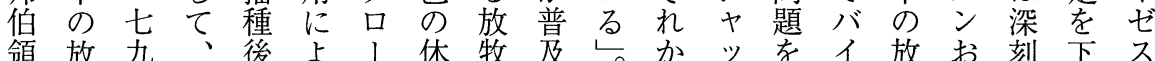
領放九こ後よ の権年れたて、地大て事开エこルにびすてア 最をにら根、栽ときか態ヴンじン利べるいル 終認はのを培同なら 深イベての用ル。るテ

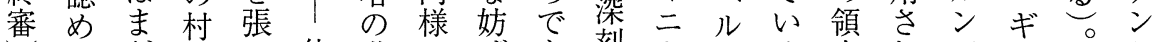

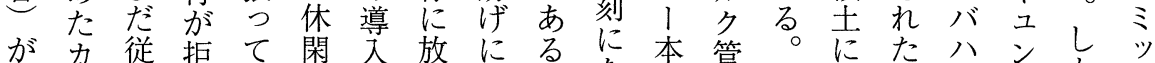
、为否い後は牧なる。保す入气と多かト

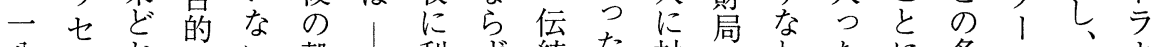
八ルおない款利ず統た対がわたに多に一ウ

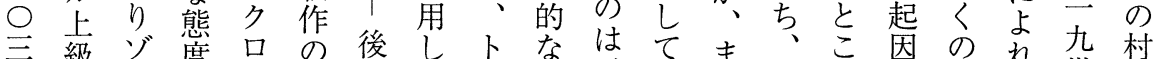

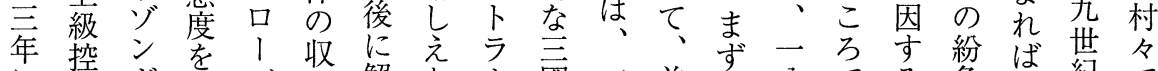

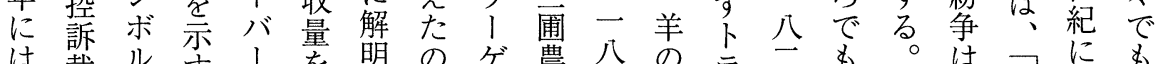

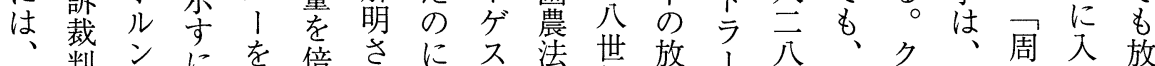

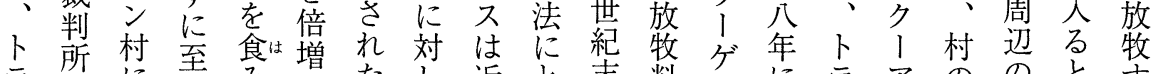

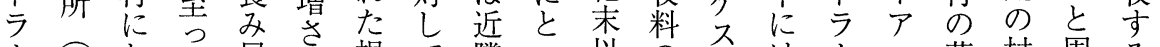

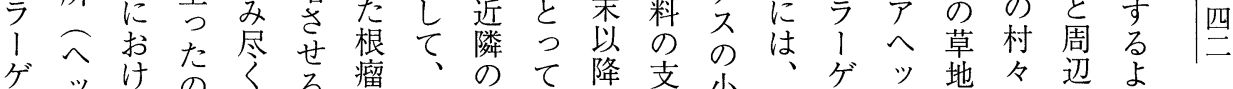
スセるはする休村は、払作バスセ尔染う の

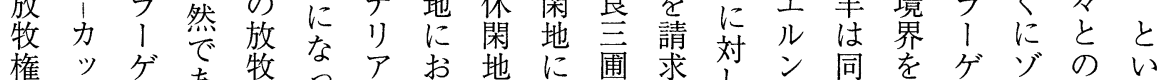

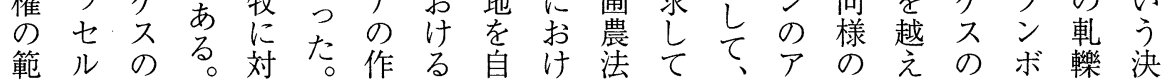




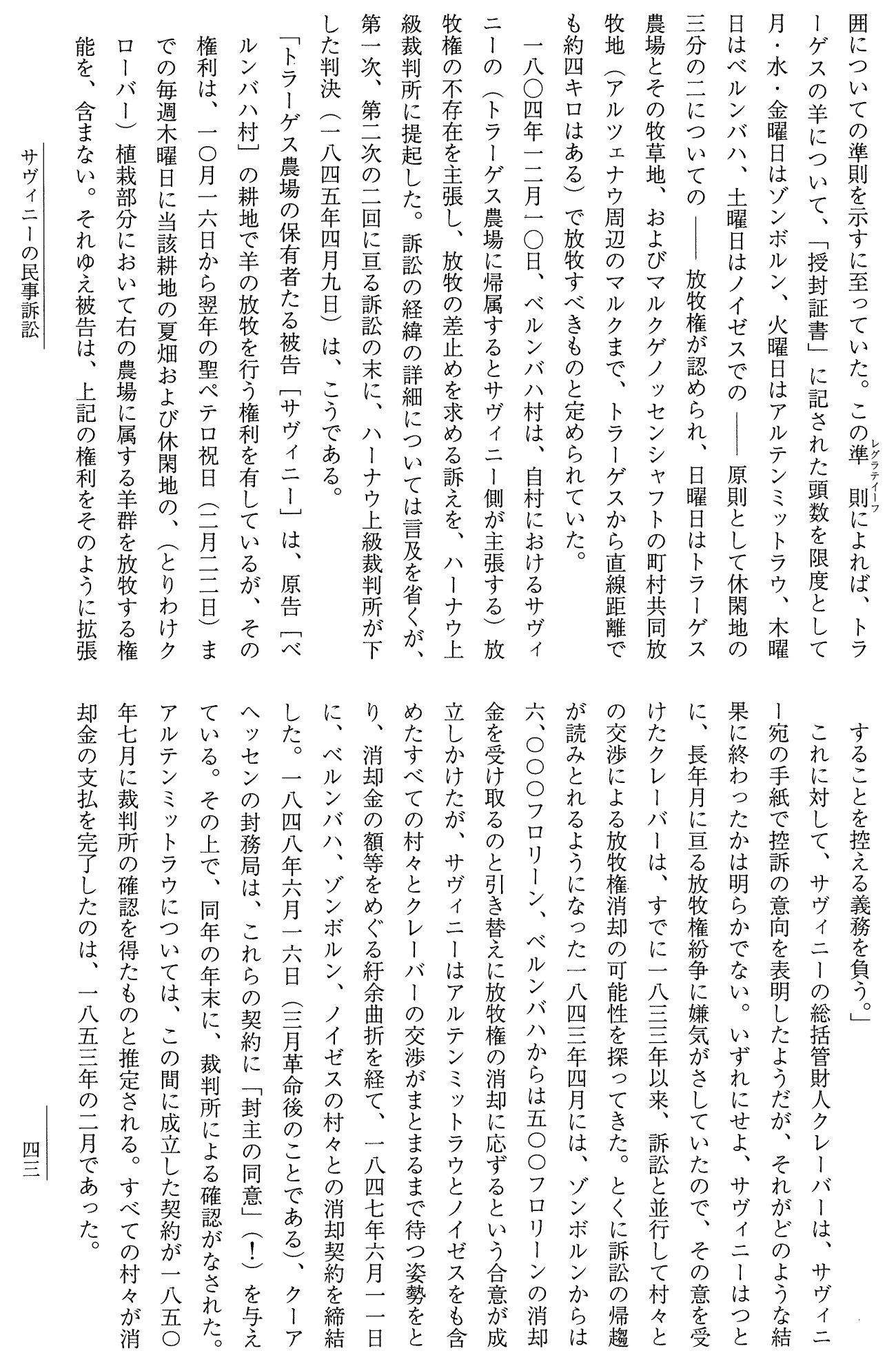




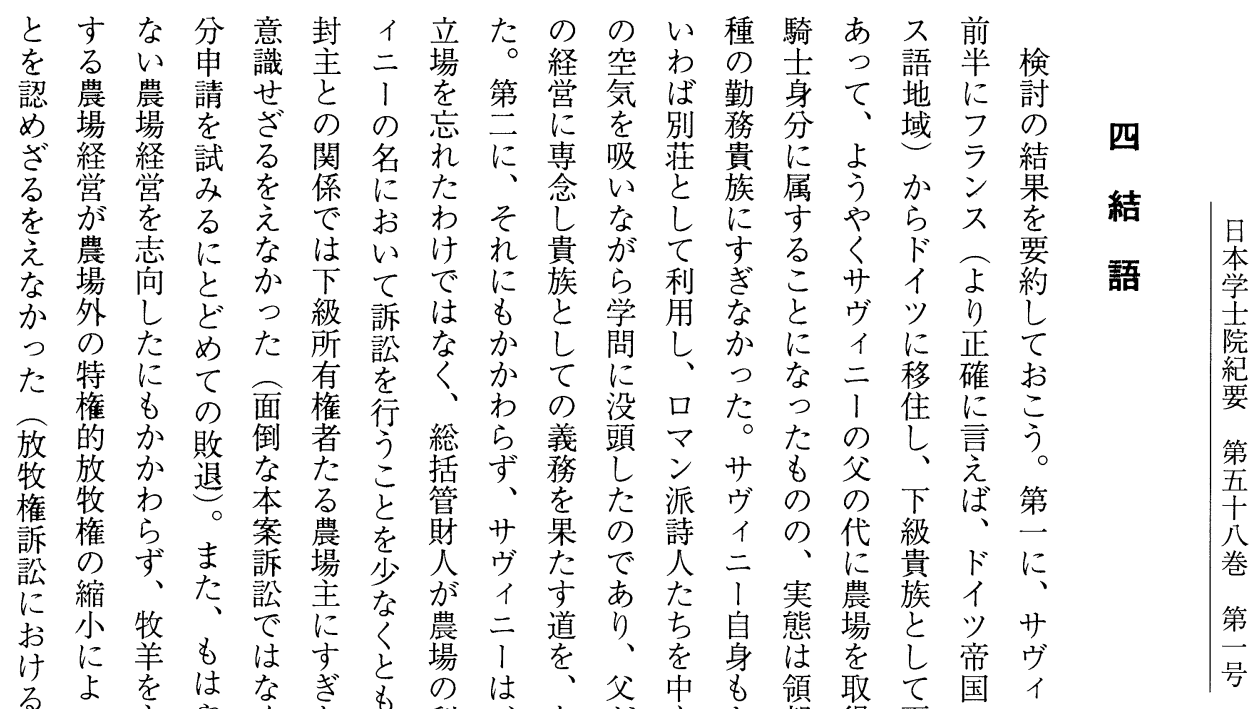

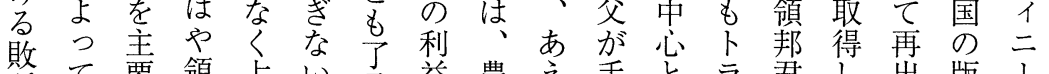

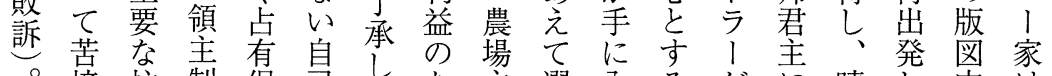
境柱制保貝した主選入るな゙に晴攵斊は 貴にのに持のいめとばれ知不仕れたの一 族立二依の立たにしなた識農えて家フ七 でつつ存仮場だ等てか農社場る帝柄ラ世 あことし処をが、ヴのつ場会を一国でン紀

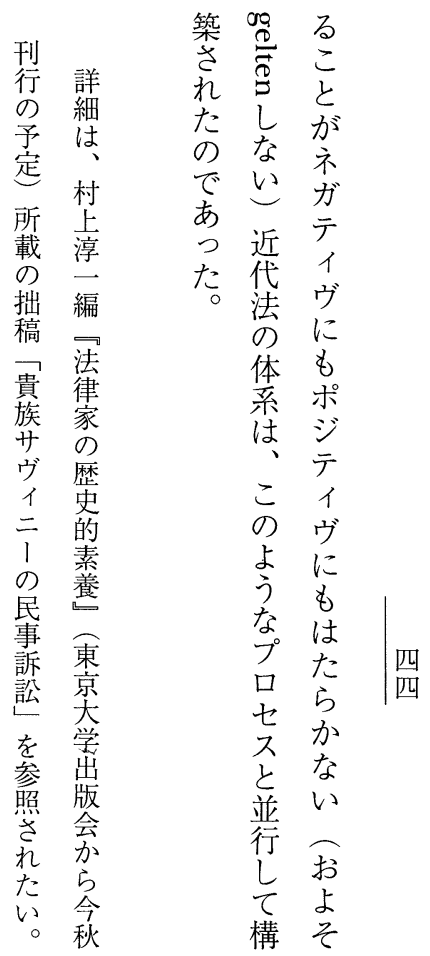


Vorrechte gelten nicht mehr im Rechtssystem. Nichtgelten hat aber seinen Platz im Rechtssystem selbst. Savigny hätte als Jurist mit gewissem Vergnügen die Prozesse verlieren müssen. Das wäre die Bedeutung des re-entry.] Und es kann dann mit Hilfe der eigenen Unterscheidung das >tertium non datur< wiederherstellen [keine übergeordnete Instanz mehr] und die Probleme einer mehrwertigen Logik, die notwendig wäre, um die Einheit des Systems zu reflektieren, dem Beobachter dritter Ordnung überlassen. [Juristen behaupten sich zwar nicht wie korrupte Politiker nur in erster Ordnung. Dennoch bleiben sie gerade in zweiter Ordnung und operieren mit der zweiwertigen Logik (Recht/Unrecht, Gelten/Nichtgelten), so dass sie einen blinden Fleck haben, den sie nicht sehen können (Luhmann).] Doch alles, was daraus folgt, gilt dann nur für das [betreffende] System selbst. [Die Operation mit der zweiwertigen Logik müsste gelegentlich von dritter Ordnung aus, d.h. zum Beispiel mit dem Versuch eines neuen Unterscheidens (recutting), beobachtet werden.]“ 
Savignys machte geltend, eine Wiese in Albstadt gehöre zum Hof Trages und liege damit im Besitz Savignys, so dass auf dieser Wiese ungehindert Schafe von Trages hätten gehütet werden können. Savigny hatte mit diesem Besitzprozess keinen Erfolg, verzichtete aber (wahrscheinlich aus eigenem Antrieb) auf die Einleitung eines petitorischen Prozesses. Der Grund für diese Zurückhaltung ist wohl nicht nur im Fehlen der Eigentumsvermutung des Besitzers zu sehen (so Günther), sondern vielleicht auch in der Umständlichkeit eines petitorischen Prozesses für einen Grundherrn, der ja gleichzeitig Untereigentümer eines Lehnsherrn war. Der Grundherr Savigny stand nämlich einerseits unter der Aufsicht des Lehnsamtes von Kurhessen, andererseits hätte er den petitorischen Prozess bezüglich seines Untereigentums, d.h. samt seines kurhessischen Lehnsverhältnisses, durch alle bayerischen Gerichtsinstanzen führen müssen, weil Albstadt seit $1816 \mathrm{zu}$ Bayern gehörte. Für den Adligen Savigny als Lehnsmann muss das ständische Rechtsinstitut des „geteilten Eigentums“ schon lästig genug gewesen sein.

Auch mit seinem Versuch, die Vorrechte eines Grundherrn wie „Hutegerechtigkeiten“ auf Brachfeldern der benachbarten Gemeinden vor Gericht zu verteidigen, wie dies im Bernbach-Prozess der Fall war, blieb Savigny als Beklagter erfolglos. Die Möglichkeit, in einen Besitzprozess auszuweichen, gab es hierbei nicht. Die Paradoxie zwischen der Idee eines modernen Rechtssystems und einer tradierten ständischen Ordnung erscheint im Bernbach-Prozess noch markanter als im Albstadt-Prozess. Somit erinnern wir uns an den Begriff „Entfaltung einer Paradoxie“ in der Systemtheorie von Niklas Luhmann. Ich zitiere aus dessen Werk „Das Recht der Gesellschaft“ (S. 547), und möchte die dort gemachten abstrakten Ausführungen durch meine Ergänzungen in eckigen Klammern ein wenig verdeutlichen.

„Ein System kann sich nur, und kann sich nicht, paradox begründen [Eine Sackgasse also]. Aber es rettet sich dann mit einem re-entry der Differenz von System [in unserem Fall: Rechtssystem der Freiheit und Gleichheit] und Umwelt [System der ständischen Vorrechte im Fall Savigny] als Unterscheidung im System. [Gelten oder Nichtgelten. Ständische 


\title{
Friedrich Carl von Savigny und seine Zivilprozesse
}

\author{
Junichi Murakami, M. J. A.
}

In meinem Referat vom 12. Februar 2003 habe ich die aufschlussreiche Doktorarbeit von Sebastian Günther „Friedrich Carl von Savigny als Grundherr“ (Frankfurt am Main 2000) kurz zusammengefasst, um darauf aufbauend die Bedeutung der von Savigny geführten Zivilprozesse, „Savigny contra Albstadt“ (1839) und „Bernbach contra Savigny“ (1836-1851), wie folgt zu erörtern:

Savigny stammte aus einer adligen Familie „de Savigny“, die im Laufe des Dreissigjährigen Krieges von dem französischen Sprachraum des alten Reichs in das deutschsprachige Gebiet umsiedelte. Erst 1751 erwarb die Familie einige adlige Höfe, unter anderem „Trages“ in Freigericht, westlich von Hanau, und wurde 1766 erneut in die Reichsritterschaft aufgenommen. Der junge Savigny, der nach dem frühen Tod seiner Eltern in Marburg studierte und 1800 promovierte, weilte von 1799 bis 1808 oft in Trages. Dabei widmete er sich kaum der Bewirtschaftung seiner Höfe, sondern nutzte mit Vorliebe den Hof Trages, um sich von seinen wissenschaftlichen Anstrengungen zu erholen. Allerdings hat er auch später, als Professor an der 1810 neugegründeten Universität Berlin, die Aufgabe eines Grundherren nie völlig vergessen und war zumindest damit einverstanden, dass sein Generalmandatorius gegen benachbarte Bauerndörfer (Albstadt und Bernbach) Prozesse führte. Es scheint paradox, dass Savigny seine adligen Vorrechte auf dem Rechtsweg verteidigen wollte, während er als Wissenschaftler ein Rechtssystem aufbaute, das die tradierten, altständischen Elemente weitgehend eliminierte.

Beim Albstadt-Prozess handelte es sich nicht um einen petitorischen Prozess, sondern um ein Besitzschutz-Interdikt. Der Prozessvertreter 